\title{
Metronomic capecitabine versus doxorubicin in advanced hepatocellular carcinoma
}

\author{
Gehan Abd Elatti Khedr', Sherif Farouk Elzawawy ${ }^{1}$, Ahmad Gaber Gowil ${ }^{1}$, Amany Saleh Elyamany ${ }^{2}$, Mohamed Eshafei ${ }^{3}$ \\ ${ }^{1}$ Clinical Oncology Department, ${ }^{2}$ Hepatology Unit, Internal Medicine Department, ${ }^{3}$ Radiology Department, Faculty of Medicine, Alexandria University, \\ Alexandria, Egypt
}

Purpose: We evaluated oral metronomic capecitabine (MC) compared to intravenous doxorubicin in patients with advanced or metastatic hepatocellular carcinoma (HCC).

Methods: From January 2013 to December 2015, patients with Child-Pugh class A or early B were randomized either to MC group (500 $\mathrm{mg}$ twice daily continuously) or doxorubicin group ( $60 \mathrm{mg} / \mathrm{m}^{2}$ every 21 days).

Results: Forty patients were included in each group. The baseline clinical characteristics of the enrolled patients were well balanced between the two groups. No complete response (CR) was reported in either group. In MC group, 2 patients (5\%) had partial response (PR), 25 patients (62.5\%) stable disease (SD) and 27 patients (67.5\%) had disease control. In doxorubicin group, 4 patients (10\%) achieved PR, 24 patients (60\%) SD and 28 patients (70\%) had disease control. The 6 months overall survival (OS) was 77.5\% for MC and 75\% for doxorubicin. The one year OS was $47.5 \%$ for MC and $42.5 \%$ for doxorubicin $(P=0.521)$. The median OS survival was 10.2 months for $M C$ and 9.6 months for doxorubicin (95\% confidence interval, 3.2-6.5). The 6 month progression-free survival (PFS) was 45\% for MC and 50\% for doxorubicin. The one year PFS was $12.5 \%$ for $\mathrm{MC}$ and $7.5 \%$ for doxorubicin $(P=0.289)$. The median time to progression was 3.4 months for $\mathrm{MC}$ and 3.1 months for doxorubicin. On multivariate analysis no significant impact for tumor stage, previous transhepatic arterial chemoembolization, portal vein thrombosis or median baseline alpha fetoprotein on OS.

Conclusion: MC showed response rate and survival outcome comparable to doxorubicin in advanced HCC but with a more favorable toxicity profile.

Keywords: Metronomic capecitabine, Doxorubicin, Hepatocellular carcinoma

\section{INTRODUCTION}

Liver cancer is the fifth most common cancer worldwide and the third most common cause of cancer mortality with more than 500,000 deaths annually. Hepatocellular carcinoma (HCC), the most common primary liver cancer, occurs in the setting of chronic liver disease and cirrhosis and is usually diagnosed late with a median survival following diagnosis of approximately 6 to 20 months [1]. HCC is clearly associated with hepatitis B and hepatitis C viral in-

Received: Apr 1, 2016 Accepted: Jun 21, 2016

Correspondence to: Gehan Abd Elatti Khedr

Clinical Oncology Department, Faculty of Medicine, Alexandria University, 17 Champlion Street, Khortoum Square, Al-Azarita, Alexandria, Egypt

Tel: +20-3484-8280 Fax: +20-3484-8280

E-mail: gkhedr@yahoo.com

Copyright (C) Korean Society of Surgical Oncology

This is an Open Access article distributed under the terms of the Creative Commons Attribution Non-Commercial License (http://creativecommons.org/licenses/by-nc/4.0) which permits unrestricted non-commercial use, distribution, and reproduction in any medium, provided the original work is properly cited. fections and chronic liver disease [2].

In Egypt, according to the 2002-2003 cancer registry, liver malignancies account for 7.5\% of all cancer cases [3]. In a single center evaluation, HCC was reported to account for about $4.7 \%$ of chronic liver disease patients. Hospital-based studies have reported an overall increase in the relative frequency of all liver related cancers (95\% as HCC), from approximately $4 \%$ in 1993 to $7.3 \%$ in 2003 [4].

Prognosis of HCC and treatment options are determined by anatomical extent of tumor (stage), biological aggressiveness (grade), cirrhosis severity (indicated by the Child-Pugh classification) and functional status. Treatment options for HCC are divided into surgical therapies (resection, cryoablation, and liver transplantation) and nonsurgical therapies, which may be liver-directed (percutaneous ethanol injection, radiofrequency ablation, transarterial chemoembolization, radiation and radioembolization) or systemic treatment (chemotherapy, molecularly targeted therapy and hormone therapy) [5]. 
Systemic chemotherapy is usually not well tolerated by patients with significant underlying hepatic dysfunction. In addition, HCC has been considered to be a relatively chemotherapy-refractory tumor. This may be in part due to the high rate of expression of drug resistance genes, including p-glycoprotein, glutathione-S-transferase, heat shock proteins, and mutations in p53 [6]. However, there still may be a role for cytotoxic chemotherapy in selected medically appropriate patients who have adequate hepatic function and a reasonable remaining life expectancy. Doxorubicin, a topoisomerase II inhibitor, has been widely used in the treatment of HCC and is one of the most active agents in this setting, with single-agent response rates of $0 \%-15 \%$. Anthracyclines have also been described as modulators of angiogenesis [7-9].

Since advanced HCC is a highly vascular tumor, several antiangiogenic drugs have shown some efficacy in this setting. Only sorafenib, which is an oral multikinase inhibitor that suppresses tumor cell proliferation and angiogenesis has proved effective in improving overall survival (OS) in patients with Child-Pugh class $A$ in randomized controlled trials $[10,11]$. However, the cost of this biological therapy limits its use in (developing) countries with limited resources [12].

Capecitabine is an antimetabolite that has shown varying degrees of efficacy with acceptable tolerability in numerous cancers with the largest amount of evidence in metastatic breast and colorectal cancer. A recent study indicated that mild-to-moderate liver dysfunction in patients with colorectal carcinoma liver metastases did not significantly affect capecitabine pharmacokinetics [13]. This finding suggests that capecitabine may be useful for patients with hepatobiliary carcinoma, including patients with mildly-to-moderately impaired hepatic function. Some preliminary and phase II studies suggested that capecitabine may be effective in advanced HCC. In addition, metronomic capecitabine (MC) was found to have a better tolerability than the standard schedule and promises good efficacy in this setting [14-16].

Metronomic chemotherapy refers to continuous administration of low-dose chemotherapy without treatment breaks, which was found to have both cytotoxic and antiangiogenic effects with a low toxicity profile. These features are particularly attractive in cirrhotic patients having highly vascular tumors (e.g., HCC), and are often unfit for conventional chemotherapy [17]. While the main target of chemotherapeutic drugs administered at the maximum tolerable dose (MTD) is the tumor cells, certain cytotoxic agents, when administered at low and frequent doses target tumour endothelium and are more effective than large single bolus doses followed by long rest periods [18]. This is because intra-tumoral vascular endothelial cells, in contrast to the endothelium of quiescent mature blood vessels of normal adult tissues, proliferate rapidly and are vulnerable to cytotoxic agents.

On the basis of these results, we evaluated oral capecitabine given in a metronomic schedule compared to intravenous doxorubicin (the most commonly studied chemotheraputic agent in $\mathrm{HCC}$ ) in patients with metastatic or locally advanced HCC not candidate for or progressed after ablative or locoregional treatment modalities.

\section{METHODS}

Patients aged $n \geq 18$ and diagnosed with metastatic or locally advanced HCC were eligible for the present phase II single institution study. Eligible patients were not candidate for or progressed after locoregional therapies that included surgical resection, local ablation, or chemoembolization techniques and didn't receive previous systemic therapy for their disease. Patients had to have WHO performance status of $\leq 1$, Child-Pugh class $A$ or early $B$, serum creatinine level $\leq 2.0 \mathrm{mg} / \mathrm{dL}$, absolute neutrophil count $\geq 1.0 \times 10^{9} / \mathrm{L}$, platelet count of $\geq 100 \times 10^{9} / \mathrm{L}$ and hemoglobin of $\geq 8.5 \mathrm{~g} / \mathrm{dL}$. Adequate baseline ejection fraction of $\geq 60 \%$ detected by echocardiography was required for patients receiving doxorubicin. Patients with Child-Pugh class $C$ or concurrent malignancy were not eligible. All patients provided written informed consent prior to therapy. Approval of the local ethics committee was obtained before study initiation.

\section{Treatment groups}

Eligible patients presented to the clinical oncology department at Alexandria main university hospital, Alexandria, Egypt during the period from January 2013 to December 2015 were randomized either to oral MC or intravenous doxorubicin.

MC group: included patients who received oral MC in a dose of $500 \mathrm{mg}$ twice daily continuously without interruption. The cycle was repeated every 21 days.

Doxorubicin group: included patients who received intravenous doxorubicin $60 \mathrm{mg} / \mathrm{m}^{2}$ every 21 days for 6 cycles $\left(360 \mathrm{mg} / \mathrm{m}^{2}\right)$. If continued benefit and lack of toxicity were observed, patients were allowed to continue doxorubicin to $450 \mathrm{mg} / \mathrm{m}^{2}$.

In both groups, treatment was continued as planned until disease (radiological) progression as defined by response evaluation criteria in solid tumors (RECIST), unacceptable toxicity, patient withdrawal, or death.

\section{Patient evaluation and response assessment}

Initial patient evaluation included complete medical history, thorough physical examination, triphasic computed tomography (CT) scan of the abdomen and pelvis, hepatitis viral markers (HCV Abs, HCV RNA by PCR and HbsAg) and alpha fetoprotein (AFP) level. A 
complete blood count and liver and renal function tests were required initially and before each chemotherapy cycle. Metastatic work-up including CT chest and/or bone scan were performed as clinically indicated. Toxicity was monitored using the National Cancer Institute Common Toxicity Criteria for Adverse Events, version 2.0 ( $\mathrm{NCl} \mathrm{CTCv2.0).} \mathrm{The} \mathrm{response} \mathrm{was} \mathrm{evaluated} \mathrm{every} \mathrm{three} \mathrm{months}$ by ultrasonography and/or triphasic CT scan as well as AFP levels.

Objective responses were validated by radiologists. Eligible patients who received a minimum of 3 cycles were considered evaluable for response. According to RECIST criteria: complete response (CR) was defined as the disappearance of all signs and symptoms of disease. Partial response (PR) was defined as a decrease of $>30 \%$ of the sum of the largest diameters of target (measurable) lesions without appearance of new lesions or progression of non-target (evaluable) lesions. To be assigned a status of response, changes in tumor measurement were confirmed by repeat assessment that was performed not less than 4 weeks after the criteria for response were first met. Stable disease (SD) was defined as no sufficient shrinkage to qualify for PR or less than a $20 \%$ increase in the sum of the largest diameters of target lesions without appearance of new lesions or progression of non-target lesions. Progressive disease (PD) was defined as a 20\% increase in the sum of the largest diameters of target lesions or as appearance of new lesions or as progression of non-target lesions.

\section{Statistical analysis}

The primary outcomes were to evaluate and compare the time to progression (TTP), and the OS between the two treatment groups. The secondary endpoints were the response rate, disease control rate, progression-free survival (PFS) and treatment related toxicities. Overall response rate per RECIST was defined as the proportion of patients with the best tumor response achieved during treatment or within 30 days after termination of chemotherapy. The time to disease progression and OS were calculated from the date of initiation of therapy to the date of progression of disease or death, respectively. For patients without documented death or progression at the time of analysis, OS was censored at the last follow-up date, and PFS was censored at the last date of tumor evaluation. Statistical analysis was done using Statistical Package for Social Sciences (SPSS ver. 20, IBM, Armonk, NY, USA) software. Kaplan-Meier survival curves were rendered for each group.

\section{RESULTS}

\section{Patient and disease characteristics}

Forty eligible patients in each treatment group received a minimum of 3 cycles of chemotherapy and were evaluable for response. The
Table 1. Demographic and clinical data of the two studied group

\begin{tabular}{|c|c|c|c|c|}
\hline Characteristic & $\begin{array}{c}\text { Group A } \\
\text { MC } \\
(n=40)\end{array}$ & $\begin{array}{c}\text { Group B } \\
\text { Doxorubicin } \\
(n=40)\end{array}$ & P-value & $\begin{array}{c}\text { Confidence } \\
\text { interval }\end{array}$ \\
\hline Age & & & 0.658 & $0.85-1.22$ \\
\hline Range & $39-71$ & $39-76$ & & \\
\hline Median & 56.0 & 56.5 & & \\
\hline Sex & & & 0.235 & $0.68-1.69$ \\
\hline Male & $38(95.0)$ & 35 (87.5) & & \\
\hline Female & $2(5.0)$ & $5(12.5)$ & & \\
\hline Smoking & $25(62.5)$ & $28(70.0)$ & 0.365 & $0.98-1.85$ \\
\hline DM & $3(7.5)$ & $4(10.0)$ & 0.633 & $0.32-2.98$ \\
\hline Hypertension & $18(45.0)$ & $21(52.5)$ & 0.625 & $0.42-2.45$ \\
\hline ECOG score & & & 0.361 & $0.77-1.98$ \\
\hline 0 & $26(65)$ & $22(55)$ & & \\
\hline 1 & $14(35)$ & $18(45)$ & & \\
\hline Bilhariziasis & $18(45.0)$ & $19(47.5)$ & 0.852 & $0.33-2.33$ \\
\hline Hepatitis C & $40(100.0)$ & $40(100.0)$ & - & - \\
\hline Hepatitis B & $10(25.0)$ & $12(30.0)$ & 0.622 & $0.62-2.01$ \\
\hline Combined $C$ and $B$ & $10(25.0)$ & $12(30.0)$ & 0.589 & $0.52-3.11$ \\
\hline Cirrhosis & 40 (100.0) & $40(100.0)$ & - & \\
\hline Jaundice & $8(20.0)$ & $5(12.5)$ & 0.108 & $0.62-2.14$ \\
\hline LL oedema & $4(10.0)$ & $5(12.5)$ & 0.611 & $0.71-1.98$ \\
\hline Ascites & $2(5.0)$ & $3(7.5)$ & 0.651 & $0.65-2.99$ \\
\hline Child class & & & 0.061 & $0.33-1.21$ \\
\hline$A$ & $34(85.0)$ & 37 (92.5) & & \\
\hline B & $6(15.0)$ & $3(7.5)$ & & \\
\hline Protal vein thrombosis & $31(77.5)$ & $28(70.0)$ & 0.411 & $0.36-1.62$ \\
\hline Previous TACE & $13(32.5)$ & $18(45.0)$ & 0.285 & $0.52-4.22$ \\
\hline \multicolumn{5}{|l|}{ TNM stage } \\
\hline$\| \mathrm{B}$ & $9(22.5)$ & $8(20.0)$ & 0.532 & $0.21-2.15$ \\
\hline$\| \mathrm{A}$ & $8(20.0)$ & $10(25.0)$ & 0.322 & $0.36-3.65$ \\
\hline$\| I I B$ & $11(27.5)$ & $7(17.5)$ & $0.042^{\mathrm{a})}$ & $0.41-0.82$ \\
\hline IV (extrahepatic disease) & $12(30.0)$ & $15(37.5)$ & 0.365 & $0.33-2.07$ \\
\hline Extrahepatic disease & $12(30.0)$ & $15(42.5)$ & 0.106 & $0.25-1.68$ \\
\hline Bone metastasis & $8(20.0)$ & $7(17.5)$ & 0.622 & $0.62-1.72$ \\
\hline Pulmonary metastasis & $1(2.5)$ & $3(7.5)$ & 0.452 & $0.32-2.65$ \\
\hline Nodal metastasis & $1(2.5)$ & $2(5.0)$ & 0.622 & $0.45-1.69$ \\
\hline $\begin{array}{l}\text { Pulmonary and nodal } \\
\text { metastasis }\end{array}$ & $2(5.0)$ & $3(7.5)$ & 0.240 & $0.62-2.01$ \\
\hline
\end{tabular}

Values are presented as number (\%).

MC, metronomic capecitabine; DM, diabetes Mellitus; ECOG, Eastern Cooperative Oncology Group; LL, lower limb; TACE, transhepatic arterial chemoembolization; TNM, tumor, node, metastasis.

a) Significant $P$-value $\leq 0.05$.

baseline clinical characteristics of the enrolled patients were well balanced among the two treatment groups and are shown in (Table 1). The median age for MC group patients was 56 years (ranging from 39 to 71 years) and for doxorubicin group patients it was 56.5 years (ranging from 39 to 76 years). Two patients (5\%) in MC group 
were females compared to five patients (12.5\%) in doxorubicin group. World Health Organization (WHO) performance status scores were 0 in 26 patients (65\%), and 1 in 14 patients (35\%) in MC group and scores were 0 in 22 patients (55\%), and 1 in 18 patients $(45 \%)$ in doxorubicin group. All patients (100\%) in each group had HCV-related liver cirrhosis. Ten patients (25\%) in MC group and twelve (30\%) patients in doxorubicin group had combined HCV and HBV. In MC group, jaundice, lower limb edema, and ascitis were seen in 8 patients (20\%), 4 patients (10\%) and 2 patients (5\%), respectively. While in doxorubicin group, jaundice, lower limb edema and ascitis were seen in 5 patients (12.5\%), 5 patients (12.5\%) and 3 patients (7.5\%), respectively. Thirty four (85\%) patients in MC group and 37 patients (92.5\%) in doxorubicin group had Child-Pugh class $A$, while six patients (15\%) in MC group and 3 patients (7.5\%) in doxorubicin group had Child-Pugh class B. Regarding tumor, node, metastasis (TNM) stage, 12 patients (30\%) in MC group had extrahepatic disease at presentation including 8 patients $(20 \%)$ with bone metastasis, one (2.5\%) with pulmonary metastasis, one (2.5\%) with nodal metastasis and 2 patients (5\%) with both bone and nodal metastasis. In doxorubicin group there were 15 patients (37.5\%) with extrahepatic disease including 7 patients (17.5\%) with bone metastasis, $3(7.5 \%)$ with pulmonary metastasis, $2(5 \%)$ with nodal metastasis and 3 patients (7.5\%) with both bone and nodal metastasis. Portal vein thrombosis was seen in 31 patients (77.5\%) in MC group compared to 28 patients (70\%) in doxorubicin group. Most patients in both groups had abnormal serum AFP level ( $>5 \mathrm{ng} / \mathrm{mL}$ ) constituting $87.5 \%$ of patients in MC group, with a median value of $240 \mathrm{ng} / \mathrm{mL}$ (range, $1.5-3,191 \mathrm{ng} / \mathrm{mL}$ ) and a mean of $632.3 \pm 858.1$ while in doxorubicin group, $92.5 \%$ of patients had abnormal AFP level with a median value of $240 \mathrm{ng} / \mathrm{mL}$ (range 1.5-4,426 ng/mL) and a mean of $720.3 \pm 1,027$. In MC group, there were 13 patients (32.5\%) who underwent previous transhepatic arterial chemoembolization (TACE) for treatment of HCC, while in doxorubicin group there were 18 patients (45.0\%) with previous TACE. Table 2 summarizes the results of pretreatment laboratory measurements. All laboratory values were similar across the two study groups except for the platelet count, which was significantly lower in doxorubicin group $(P=0.029)$.

There was no CR reported in either group. In MC group, 2 patients (5\%) achieved PR and 25 patients (62.5\%) had SD while in doxorubicin group, 4 patients (10\%) achieved PR and 24 patients $(60 \%)$ had SD. PD was seen in 13 patients (32.5\%) in MC group and in 12 patients (30\%) in doxorubicin group. There was no significant difference between the two groups regarding response rate $(P=0.695)$. The disease control rate $(C R+P R+S D)$ was $67.5 \%$ in $M C$ group and $70 \%$ in doxorubicin group with no significant difference. The 6 month PFS was 45\% for MC group and 50\% for doxorubicin
Table 2. Pretreatment laboratory investigations in the two studied groups

\begin{tabular}{|c|c|c|c|c|}
\hline $\begin{array}{l}\text { Laboratory } \\
\text { findings }\end{array}$ & $\begin{array}{c}\text { Group A } \\
\text { MC } \\
(n=40)\end{array}$ & $\begin{array}{c}\text { Group B } \\
\text { Doxorubicin } \\
(n=40)\end{array}$ & P-value & $\begin{array}{c}\text { Confidence } \\
\text { interval }\end{array}$ \\
\hline Platelet count & & & $0.029^{a)}$ & $0.11-0.95$ \\
\hline Range & $150-350$ & $150-350$ & & \\
\hline Mean $\pm S D$ & $244.8 \pm 52.5$ & $222.4 \pm 51.8$ & & \\
\hline Median & 250.0 & 210.0 & & \\
\hline SGPT & & & 0.280 & $0.32-2.33$ \\
\hline Range & $14-64$ & $14-63$ & & \\
\hline Mean \pm SD & $30.4 \pm 13.2$ & $32.1 \pm 12.0$ & & \\
\hline Median & 27.5 & 30.5 & & \\
\hline SGOT & & & 0.097 & $0.36-1.89$ \\
\hline Range & $26-74$ & $24-85$ & & \\
\hline Mean $\pm S D$ & $43.5 \pm 13.7$ & $47.9 \pm 15.9$ & & \\
\hline Median & 39.5 & 44.0 & & \\
\hline Hemoglobin & & & 0.173 & $0.72-3.11$ \\
\hline Range & $9.5-13.5$ & $9.5-13.5$ & & \\
\hline Mean $\pm S D$ & $11.6 \pm 1.1$ & $14.0 \pm 16.2$ & & \\
\hline Median & 11.5 & 11.5 & & \\
\hline AFP & & & 0.346 & $0.25-3.65$ \\
\hline Range & $1.5-3,191$ & $1.5-4,426$ & & \\
\hline Mean $\pm S D$ & $632.3 \pm 858.1$ & $720.3 \pm 1,027.0$ & & \\
\hline Median & 240.0 & 240.0 & & \\
\hline S bilirubin & & & 0.162 & $0.33-2.68$ \\
\hline Range & $0.8-4.3$ & $0.6-4.3$ & & \\
\hline Mean $\pm S D$ & $1.4 \pm 0.8$ & $1.2 \pm 0.6$ & & \\
\hline Median & 1.1 & 1.1 & & \\
\hline Protein & & & 0.217 & $0.65-2.87$ \\
\hline Range & $4-7$ & $4-7$ & & \\
\hline Mean $\pm S D$ & $5.9 \pm 0.7$ & $6.0 \pm 0.6$ & & \\
\hline Median & 6.0 & 6.0 & & \\
\hline Albumin & & & 0.324 & $0.75-2.33$ \\
\hline Range & $2.5-4.0$ & $2.5-4$ & & \\
\hline Mean \pm SD & $3.3 \pm 0.4$ & $3.2 \pm 0.3$ & & \\
\hline Median & 3.3 & 3.2 & & \\
\hline INR & & & 0.061 & $0.36-1.24$ \\
\hline Range & $1-1.5$ & $1-1.5$ & & \\
\hline Mean $\pm S D$ & $1.1 \pm 0.2$ & $1.1 \pm 0.1$ & & \\
\hline Median & 1.0 & 1.0 & & \\
\hline
\end{tabular}

MC, metronomic capecitabine; SD, standard deviation; SGPT, serum glutamic oxalacetic transaminase; SGOT, serum glutamic pyruvic transaminase; AFP, alpha fetoprotein; INR, international normalized ratio; TNM, tumor, node, metastasis.

${ }^{\text {a) } M e a n s ~ s i g n i f i c a n t ~} \mathrm{P}$-value $\leq 0.05$.

group, while the one year PFS was $12.5 \%$ for MC and $7.5 \%$ for doxorubicin. There was no statistically significant difference in PFS between the two groups $(P=0.289)$ as shown in Table 3 and Fig. 1 . The median TP was 3.4 months for MC group and 3.1 months for 
Table 3. Comparison between the two studied groups regarding progression free survival

\begin{tabular}{lcc}
\hline Progression free survival & $\begin{array}{c}\text { Group A } \\
\text { MC } \\
(n=40)\end{array}$ & $\begin{array}{c}\text { Group B } \\
\text { Doxorubicin } \\
(\mathrm{n}=40)\end{array}$ \\
\hline 0 Month & $40(100.0)$ & $40(100.0)$ \\
3 Months & $30(75.0)$ & $38(95.0)$ \\
6 Months & $18(45.0)$ & $20(50.0)$ \\
9 Months & $16(40.0)$ & $15(37.5)$ \\
12 Months & $4(10.0)$ & $3(7.5)$ \\
15 Months & $5(12.5)$ & $3(7.5)$ \\
18 Months & $3(7.5)$ & $1(2.5)$ \\
21 Months & 0 & 0 \\
P-value & \multicolumn{3}{c}{0.289} \\
Confidence interval of mean 95.0\% & \multicolumn{3}{c}{$3.20-6.1$} \\
\hline
\end{tabular}

Values are presented as number (\%).

$M C$, metronomic capecitabine.

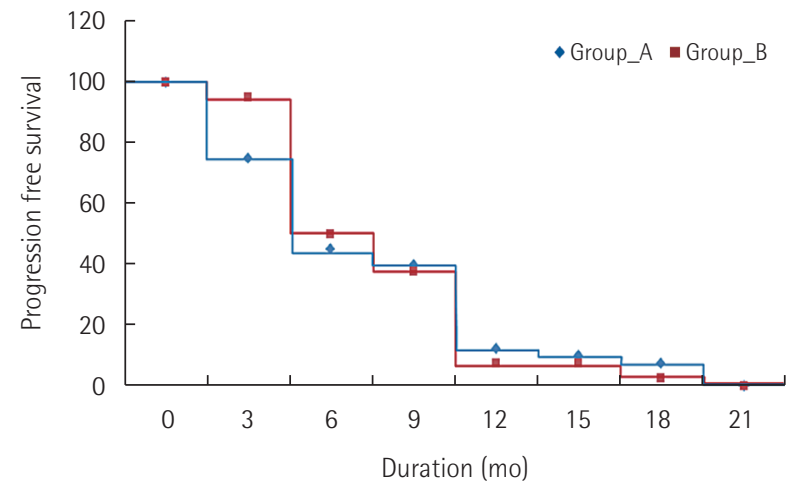

Fig. 1. Comparison between the two studied groups regarding progression free survival. Group $A_{\text {, metronomic capecitabine group; }}$ Group B, Doxorubicin group.

doxorubicin group. The 6 months OS was 77.5\% for MC group and $75 \%$ for doxorubicin group. The median OS survival was 10.2 months for MC group and 9.6 months for doxorubicin group. The one year OS was 47.5\% for MC group and 42.5\% for doxorubicin group. Also, there was no statistically significant difference in OS between the two groups $(P=0.521)$ as shown in Table 4 and Fig. 2. Reduction in the level of AFP compared to baseline level was reported in 60\% of patients in MC group and 67.5\% in doxorubicin group patients. The effects of different prognostic factors on OS were evaluated using multivariate analysis which included combined hepatitis $B$ and $C$ virus, tumor stage, previous TACE, portal vein thrombosis, and median baseline AFP. However, none had significant prognostic impact on survival (Table 5).

\section{Toxicity and dose modifications}

In MC group, two patients (5\%) had grade II hand and foot syn-
Table 4. Comparison between the two studied groups regarding overall survival and median survival

\begin{tabular}{lcc} 
Overall survival & $\begin{array}{c}\text { Group A } \\
\text { MC } \\
(\mathrm{n}=40)\end{array}$ & $\begin{array}{c}\text { Group B } \\
\text { Doxorubicin } \\
(\mathrm{n}=40)\end{array}$ \\
\hline 0 Month & $40(100.0)$ & $40(100.0)$ \\
3 Months & $36(90.0)$ & $35(87.5)$ \\
6 Months & $31(77.5)$ & $30(75.0)$ \\
9 Months & $28(70.0)$ & $25(62.5)$ \\
12 Months & $17(42.5)$ & $17(42.5)$ \\
15 Months & $15(37.5)$ & $16(40.0)$ \\
18 Months & $10(25.0)$ & $10(25.0)$ \\
21 Months & $5(12.5)$ & $6(10.0)$ \\
Median survival (mo) & 10.2 & 9.6 \\
P-value & \multicolumn{3}{c}{0.521} \\
Confidence interval of mean 95.0\% & \multicolumn{3}{c}{$0.32-6.5$} \\
Confidence interval & \multicolumn{3}{|c}{} \\
\hline
\end{tabular}

Values are presented as number $(\%)$.

$\mathrm{MC}$, metronomic capecitabine.

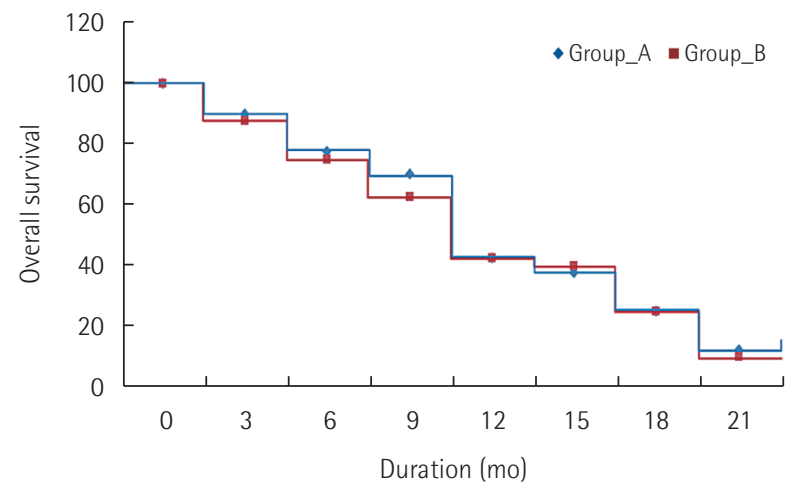

Fig. 2. Comparison between the two studied groups regarding overall survival. Group A, metronomic capecitabine group; Group B, Doxorubicin group.

drome and 5 patients (12.5\%) experienced one or more episodes of grade I/II diarrhea, which was treated by loperamid, and treatment was discontinued for up to one week then was resumed after cessation of diarrhea. In addition, 8 patients developed hyperbilirubinemia and elevated enzymes and 3 patients developed encephalopathy, which were related to disease progression. There were no grade II or higher hematological toxicities.

Meanwhile, in doxorubicin group, doxorubicin at $60 \mathrm{mg} / \mathrm{m}^{2}$ was well tolerated by the majority of patients. All patients experienced alopecia, 95\% had nausea and vomiting, and 20\% developed hyper-pigmentation that manifested by the darkening of fingers and toes, with or without the entire complexion. One patients $(2.5 \%)$ developed treatment-emergent left-ventricular systolic dysfunction. Five patients (12.5\%) developed elevated hepatic enzymes and 2 
Table 5. Relation between overall survival at one year and other factors

\begin{tabular}{|c|c|c|c|c|c|c|}
\hline \multirow[t]{2}{*}{ Prognostic factors } & \multicolumn{3}{|c|}{$\begin{array}{c}\text { Group A } \\
M C(n=40)\end{array}$} & \multicolumn{3}{|c|}{$\begin{array}{c}\text { Group B } \\
\text { Doxorubicin }(n=40)\end{array}$} \\
\hline & Die $(n=23)$ & Survive $(n=17)$ & P-value & Die $(n=23)$ & Survive $(n=17)$ & P-value \\
\hline Combined $B$ and $C$ virus & $8(3.5)$ & $2(11.8)$ & 0.069 & $15(6.5)$ & $13(76.5)$ & 0.363 \\
\hline TNM stage & & & 0.307 & & & 0.399 \\
\hline$\| B$ & $3(33.3)$ & $6(66.7)$ & & $4(50.0)$ & $4(50.0)$ & \\
\hline IIIA & $6(75.0)$ & $2(25.0)$ & & $4(40.0)$ & $6(60.0)$ & \\
\hline$\| \mathrm{IIB}$ & $6(54.5)$ & $5(45.5)$ & & $4(57.1)$ & $3(42.9)$ & \\
\hline IV & $8(66.7)$ & $4(33.3)$ & & $11(73.3)$ & $4(26.7)$ & \\
\hline Previous TACE & $12(5.2)$ & $1(5.9)$ & 0.622 & $16(7.0)$ & $2(11.8)$ & 0.265 \\
\hline Portal vein thrombosis & 19 (63.3) & $11(36.7)$ & 0.099 & $18(66.7)$ & $9(33.3)$ & 0.089 \\
\hline Median AFP & 245.0 & 230.0 & 0.225 & 250.0 & 235.0 & 0.199 \\
\hline
\end{tabular}

Values are presented as number (\%).

MC, metronomic capecitabine; TNM, tumor node metastasis; TACE, transhepatic arterial chemoembolization; AFP, alpha fetoprotein.

(5\%) had hyperbilirubinemia believed to be potentially doxorubicin-related, treatment was discontinued and then resumed with a dose reduction of 25\%. As regarding hematological toxic effects, 6 patients had grade II anemia, 10 patients had grade II thrombocytopenia and 5 patients developed grade II neutropenia, those patients required temporal cessation of doxorubicin until hematological recovery. There were no grade III/IV hematological toxicities. In both groups, no treatment related death was reported. The difference in toxicity profile was statistically significant between the two groups as regarding diarrhea, which was seen in $\mathrm{MC}(\mathrm{P}=0.044)$; nausea and vomiting $(P=0.001)$, alopecia $(P=0.0001)$, hyperpigmentation $(P=0.013)$, neutropenia $(P=0.028)$ and elevated hepatic enzymes $(P=0.044)$ (Table 6).

\section{DISCUSSION}

Treatment of patients with advanced HCC presents a major challenge because associated cirrhosis limits the choice of chemotherapeutic agents. In addition, no effective systemic therapy (hormonal therapy or cytotoxic chemotherapy) has improved survival in those patients [19] with no single or combination agents giving response rates $>25 \%$ [20]. Only sorafenib is proven to demonstrate a survival benefit in advanced HCC for selected patients with Child-Pugh class $A, B[10,11]$. However, the absolute advantage is considered still unsatisfactory (2.8 months among Western patients and 2.3 months among Asian patients) and is achieved at the expense of frequent toxicity. In fact, up to $38 \%$ of patients discontinue treatment because of adverse events, and around 26\% of patients require a dose reduction [16]. In addition, high cost and unavailability are considered limitations to the routine use of sorafenib, especially in limited resource countries [12]. So, additional studies of potential systemic chemotherapy for the treatment of advanced HCC are
Table 6. Comparison between the studied groups regarding treatment toxicities

\begin{tabular}{|c|c|c|c|}
\hline Toxicity & $\begin{array}{c}\text { Group A } \\
\text { MC } \\
(n=40)\end{array}$ & $\begin{array}{c}\text { Group B } \\
\text { Doxorubicin } \\
(n=40)\end{array}$ & P-value \\
\hline Hand and foot syndrome & $2(5.0)$ & 0 & 0.32 \\
\hline Diarrhea & $5(12.5)$ & 0 & $0.044^{*}$ \\
\hline Nausea, vomiting & $3(7.5)$ & $38(95.0)$ & $0.001^{*}$ \\
\hline Alopecia & 0 & $40(100.0)$ & $0.0001^{*}$ \\
\hline Hyper-pigmentation & 0 & $8(20.0)$ & $0.013^{*}$ \\
\hline Left-ventricular systolic dysfunction & 0 & $1(2.5)$ & 0.65 \\
\hline Hyperbilirubinemia & 0 & $2(5.0)$ & 0.32 \\
\hline Elevated hepatic enzymes & 0 & $5(12.5)$ & $0.044^{*}$ \\
\hline \multicolumn{4}{|l|}{ Anemia } \\
\hline Grade 1/2 (Hgb 8-9 g/dL) & $4 / 0(10 / 0)$ & $2 / 6(5 / 15)$ & 0.09 \\
\hline Grade 3/4 (Hgb < 8 g/dL) & 0/0 (0/0) & 0/0 (0/0) & - \\
\hline \multicolumn{4}{|l|}{ Thrombocytopenia } \\
\hline Grade 1/2 (PLT, 50-75× $\left.10^{3} \mu / \mathrm{L}\right)$ & $3 / 0(7.5 / 0)$ & $3 / 10(7.5 / 25.0)$ & 0.081 \\
\hline Grade $3 / 4\left(\mathrm{PLT}<50 \times 10^{3} \mu / \mathrm{L}\right)$ & $0 / 0(0 / 0)$ & $2 / 0(5 / 0)$ & 0.366 \\
\hline \multicolumn{4}{|l|}{ Neutropenia } \\
\hline 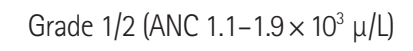 & 0/0 (10/0) & $2 / 5(5.0 / 12.5)$ & $0.028^{*}$ \\
\hline Grade $3 / 4\left(\right.$ ANC $\left.<1.0 \times 10^{3} \mu / L\right)$ & $0 / 0(0 / 0)$ & $0 / 0(0 / 0)$ & - \\
\hline
\end{tabular}

Values are presented as number $(\%)$.

MC, metronomic capecitabine; Left-ventricular systolic dysfunction, defined as ejection fraction < 50\%; Hyperbilirubinemia, defined as total serum bilirubin $>3 \mathrm{mg} / \mathrm{dL}$; Elevated hepatic enzymes, defined as doubling of serum glutamic oxalacetic transaminase nadir level; $H g b$, hemoglobin; PLT, platelet; ANC, absolute neutrophil count. ${ }^{*}$ Means significant P-value $\leq 0.05$.

needed, especially after the promising results of some chemotherapeutic regimens [21].

Being one of the most active chemotherapeutic agents in advanced HCC [7-9], doxorubicin was considered the control arm to which MC was compared in our study. Although the optimal met- 
ronomic dose is not known for many drugs and diseases, doses of MC closely similar to doses used in our study were found to be safe and effective in HCC and other malignancies. A dose of capecitabine of $500 \mathrm{mg}$ twice daily was shown to have cytotoxic and anti-angiogenic effectiveness in colorectal cancer [22]. In addition, a fixed daily dose of 1,000 $\mathrm{mg}$ of MC was found to be a safe and valid treatment option in advanced colorectal and gastric cancer patients [23]. A dose of $650 \mathrm{mg} / \mathrm{m}^{2}$ of MC twice daily continuously improved OS by being similarly active, less toxic, and more tolerable than classical CMF and considered a good option for women unsuited to more intensive regimens as first-line chemotherapy for advanced breast cancer [24]. In advanced HCC, Brandi et al. [14] studied MC in patients with Child A disease where the first cycle was carried out with standard capecitabine $\left(2,000 \mathrm{mg} / \mathrm{m}^{2} /\right.$ day; 14 over 21 days), followed by MC (1,300 mg) daily without interruption. They indicated that MC had a better tolerability than standard schedule and promises good efficacy. In another study by Brandi et al. [16] they used MC at a dose of $500 \mathrm{mg}$ twice daily till disease progression or toxicity and indicated that $\mathrm{MC}$ is well tolerated by patients with advanced HCC and appears to have activity both in treatment-naive patients and in those previously treated with sorafenib. Also, Farrag et al. [25] studied MC in patients with advanced $\mathrm{HCC}$ at a dose of $1,000 \mathrm{mg} / \mathrm{m}^{2} /$ day without interruption and showed modest antitumor activity and low toxicity profile. Based on these data, patients in our study received MC at a dose of 500 mg twice daily continuously without interruption.

In the current study, there was no CR documented in all study patients. The response rate was 5\% in MC and 10\% in doxorubicin treated patients while the disease control rate was $67.5 \%$ in $\mathrm{MC}$ and $70 \%$ in doxorubicin treated patients with no significant difference between the two groups. These results are comparable to the low response rate reported for many single chemotherapeutic agents in advanced HCC, which is generally less than 10\% [26]. Lai et al. [8] reported that single agent doxorubicin had a response rate of about 10\%-15\%, with no proven survival benefit. Studies on MC for advanced HCC showed comparable results but a higher response rate. For example, Brandi et al. [15] reported an objective response of $14.1 \%$ and disease control of $66.7 \%$. Farrag et al. [25], reported an objective response rate of $16 \%$ and disease control rate of $69 \%$. Recently Mateen et al. [27], used MC at a similar dose to that used in our study and reported 3.6\% CR, 21.8\% PR, 34.5\% SD, and 40\% progressive disease in 55 newly diagnosed patients with advanced HCC. In another trial by Brandi et al. [16], two patients achieved $\mathrm{CR}$, one patient achieved $\mathrm{PR}$, and 30 patients had SD with $\mathrm{MC}$ in 59 previously untreated patients with HCC.

In our study, the median TP was 3.4 months for MC group and 3.1 months for doxorubicin group. The median OS survival was 10.2 months for $\mathrm{MC}$ group and 9.6 months for doxorubicin group. The one year OS was 47.5\% for MC group and 42.5\% for doxorubicin group. Our survival outcomes for MC were consistent with what was reported by Patt et al. [28], who described a median survival duration of 10.1 months (95\% confidence interval [Cl], 4.5-15.7 months) for patients with HCC treated with capecitabine at a dose of $1,000 \mathrm{mg} / \mathrm{m}^{2}$ twice daily for 14 days followed by one week of rest. However, our results were better than those by Farrag et al. [25], who reported a median TTP of 2.2 months (95\% Cl 1.4-6.24), median survival time of 4.8 months (95\% Cl 1.8-7.9), and 6 months OS of 70\%, and PFS of $44 \%$ for patients on MC. While Brandi et al. [16], reported a higher median PFS of 6.03 months and an OS of 14.47 months for MC. In general, the low survival outcomes observed in our study were similar to most chemotherapy agents who failed to show a survival benefit in patients with advanced HCC.

In the current study, we reported reductions in the level of AFP compared to baseline levels in 60\% of patients in MC group and $67.5 \%$ of patients in doxorubicin group. These results were comparable to what was reported by Mateen et al. [27], as thirty nine patients (70.9\%) had significant reduction in AFP levels with MC. Also, Patt et al. [28], reported a significant decrease in follow-up AFP serum levels compared to the baseline values among patients with HCC who achieved CR or PR $(P=0.04)$. The estimated median decrease was 86\% (range, 86\%-99\%).

The toxicity profile for patients in our study was different between the two treatment groups. Nausea, vomiting, alopecia, hyper-pigmentation, and elevated hepatic enzymes were common in the doxorubicin group patients. In addition hematological toxicities were more frequent in the doxorubicin group and included grade II toxic effects, which required temporal cessation of treatment till hematological recovery. The adverse events in doxorubicin treated patients in this study were consistent with those observed in previous studies of doxorubicin in advanced HCC [7]. While in MC group, hematological toxicities were much less common and limited to grade I, and didn't require treatment modification compared to doxorubicin treated patients. Also, diarrhea and hand-foot skin reactions were observed in $12.5 \%$ and $5 \%$ of patients, respectively, and were limited to grade I and II toxicities. Similarly, Farrag et al. [25], reported no grade III/IV hematological toxic effects with MC and only grade I and II thrombocytopenia (20\%) and grade I anemia (10\%). Non-hematological toxic effects included grade III vomiting and diarrhea reported in one patient (5\%), grade III hand-foot syndrome in one patient (5\%) and grade I elevated hepatic enzymes (20\%). There was no treatment-related mortality. Studies on capecitabine given at MTD showed more frequent attacks of diarrhea and hand-foot skin reactions including grade III and IV toxicities. Patt et al. [28], studied capecitabine at MTD in patients with 
hepatobilliary cancer and reported that the most common toxicity was hand-foot syndrome (37\%), while grade III thrombocytopenia occurred in $8 \%$ of 37 patients with HCC. von Delius et al. [29], reported that capecitabine (MTD 2,000 $\mathrm{mg} / \mathrm{m}^{2}$ per day for 14 days) was a safe for treatment of patients with $\mathrm{HCC}$, including those with compensated cirrhosis. However, the objective response rate was limited. The toxic effects included mild myelosuppression, mild nausea and emesis, grade III diarrhea in one patient (resolved to grade I under treatment with loperamid), and grade III hand-foot skin reaction in 2 patients (was manageable by topical treatment during further course).

Abdel-Rahman et al. [30], compared capecitabine to sorafenib and found that hand-foot skin reaction was more frequent in the sorafenib group, hyperbilirubinemia was more common in the capecitabine group, and diarrhea was equivalent between both groups.

Based on previous results, most adverse effects of $M C$ were mild to moderate and manageable with supportive care or a brief drugfree period, with no dose modification required. No treatment-related deaths were observed, and no patient withdrew from treatment because of adverse events.

MC was a well-tolerated oral home treatment that didn't require hospital admission or intravenous line insertion. Treatment was convenient and side effects were considered negligible. MC showed response rate and survival outcome comparable to doxorubicin but with more favorable toxicity profile. This data supports further use of MC in advanced HCC in combination with other chemotherapeutic agents or with sorafenib to increase response rate and survival outcomes.

\section{CONFLICT OF INTEREST}

No potential conflict of interest relevant to this article was reported.

\section{REFERENCES}

1. Parkin DM, Bray F, Ferlay J, Pisani P. Estimating the world cancer burden: Globocan 2000. Int J Cancer 2001;94:153-6.

2. Beasley RP, Hwang LY, Lin CC, Chien CS. Hepatocellular carcinoma and hepatitis B virus: a prospective study of 22707 men in Taiwan. Lancet 1981;2:1129-33.

3. National Cancer Institute. Egypt cancer registry 2002-2003 [Internet]. Giza: Cairo University; [cited 2011 Aug 2]. Available from: http://www.nci.cu.edu.eg/lectures/NCl\%20registry\%2020 02-03. pdf.

4. el-Zayadi AR, Badran HM, Barakat EM, Attia Mel D, Shawky S, Mohamed MK, et al. Hepatocellular carcinoma in Egypt: a single cen- ter study over a decade. World J Gastroenterol 2005;11:5193-8.

5. Shiina S, Teratani T, Obi S, Hamamura K, Koike Y, Omata M. Nonsurgical treatment of hepatocellular carcinoma: from percutaneous ethanol injection therapy and percutaneous microwave coagulation therapy to radiofrequency ablation. Oncology 2002;62 Suppl 1:64-8.

6. Ng IO, Liu CL, Fan ST, Ng M. Expression of P-glycoprotein in hepatocellular carcinoma: adeterminant of chemotherapy response. Am J Clin Pathol 2000;113:355-63.

7. Lai $\mathrm{CL}$, Wu PC, Chan GC, Lok AS, Lin HJ. Doxorubicin versus no antitumor therapy in inoperable hepatocellular carcinoma: a prospective randomized trial. Cancer 1988;62:479-83.

8. Lai EC, Choi TK, Cheng CH, Mok FP, Fan ST, Tan ES, et al. Doxorubicin for unresectable hepatocellular carcinoma: a prospective study on the addition of verapamil. Cancer 1990;66:1685-7.

9. Wakabayashi I, Groschner K. Vascular actions of anthracycline antibiotics. Curr Med Chem 2003;10:427-36.

10. Llovet JM, Ricci S, Mazzaferro V, Hilgard P, Gane E, Blanc JF, et al. Sorafenib in advanced hepatocellular carcinoma. N Engl J Med 2008;359:378-90.

11. Cheng AL, Kang YK, Chen Z, Tsao CJ, Oin S, Kim JS, et al. Efficacy and safety of sorafenib in patients in the Asia-Pacific region with advanced hepatocellular carcinoma: a phase III randomised, double-blind, placebo-controlled trial. Lancet Oncol 2009;10:25-34.

12. Galle PR. Sorafenib in advanced hepatocellular carcinoma: we have won a battle not the war. J Hepatol 2008;49:871-3.

13. Twelves C, Glynne-Jones R, Cassidy J, Schuller J, Goggin T, Roos B, et al. Effect of hepatic dysfunction due to liver metastases on the pharmacokinetics of capecitabine and its metabolites. Clin Cancer Res 1999;5:1696-702.

14. Brandi G, Fanello S, Piscaglia F, Falanga A, Bolondi L, Flori S, et al. Metronomic capecitabine in advanced patients with hepatocellular carcinoma (HCC): preliminary results. J Clin Oncol 2007;25(18 suppl): 15163.

15. Brandi G, de Rosa F, Agostini V, di Girolamo S, Andreone P, Bolondi $L$, et al. Metronomic capecitabine in advanced hepatocellular carcinoma patients: a phase II study. Oncologist 2013;18:1256-7.

16. Brandi $G$, Agostini $V$, de Rosa $F$, et al. Metronomic capecitabine in Child-Pugh a patients with unresectable hepatocellular carcinoma. Proceeding of the 2010 Gastrointestinal Cancers Symposium; 2010 Jan 22-24; Orlando (FL), USA.

17. Kerbel RS, Kamen BA. The anti-angiogenic basis of metronomic chemotherapy. Nat Rev Cancer 2004;4:423-36.

18. Bertolini F, Paul S, Mancuso P, Monestiroli S, Gobbi A, Shaked Y, et al. Maximum tolerable dose and low-dose metronomic chemotherapy have opposite effects on the mobilization and viability of circulating endothelial progenitor cells. Cancer Res 2003;63: 
4342-6.

19. Lopez PM, Villanueva A, Llovet JM. Systematic review: evidence-based management of hepatocellular carcinoma: an updated analysis of randomized controlled trials. Aliment Pharmacol Ther 2006;23:1535-47.

20. Nerenstone SR, Ihde DC, Friedman MA. Clinical trials in primary hepatocellular carcinoma: current status and future directions. Cancer Treat Rev 1988;15:1-31.

21. Nakamura M, Nagano H, Marubashi S, Miyamoto A, Takeda Y, Kobayashi $S$, et al. Pilot study of combination chemotherapy of $S-1$, a novel oral DPD inhibitor, and interferon-alpha for advanced hepatocellular carcinoma with extrahepatic metastasis. Cancer 2008;112:1765-71.

22. Steinbild $S$, Arends J, Medinger $M$, Haring $B$, Frost $A$, Drevs J, et al. Metronomic antiangiogenic therapy with capecitabine and celecoxib in advanced tumor patients: results of a phase II study. Onkologie 2007;30:629-35.

23. Nannini M, Nobili E, Di Cicilia R, Brandi G, Maleddu A, Pantaleo $M A$, et al. To widen the setting of cancer patients who could benefit from metronomic capecitabine. Cancer Chemother Pharmacol 2009;64:189-93.

24. Stockler MR, Harvey VJ, Francis PA, Byrne MJ, Ackland SP, Fitzhar- ris $B$, et al. Capecitabine versus classical cyclophosphamide, methotrexate, and fluorouracil as first-line chemotherapy for advanced breast cancer. J Clin Oncol 2011;29:4498-504.

25. Farrag A. Efficacy and toxicity of metronomic capecitabine in advanced hepatocellular carcinoma. J Cancer The 2012;3:71-7.

26. Nowak AK, Chow PK, Findlay M. Systemic therapy for advanced hepatocellular carcinoma: a review. Eur J Cancer 2004;40:147484.

27. Mateen A, Adil AR. Role of metronomic capecitabine in advanced hepatocellular carcinoma. J Clin Oncol 2014;32 suppl:e15119.

28. Patt $Y Z$, Hassan MM, Aguayo A, Nooka AK, Lozano RD, Curley SA, et al. Oral capecitabine for the treatment of hepatocellular carcinoma, cholangiocarcinoma, and gallbladder carcinoma. Cancer 2004;101:578-86.

29. von Delius S, Lersch C, Mayr M, Stock K, Schulte-Frohlinde $E_{\text {, }}$ Schmid RM, et al. Capecitabine for treatment of advanced hepatocellular carcinoma. Hepatogastroenterology 2007;54:2310-4.

30. Abdel-Rahman 0, Abdel-Wahab M, Shaker M, Abdel-Wahab S, Elbassiony M, Ellithy M. Sorafenib versus capecitabine in the management of advanced hepatocellular carcinoma. Med Oncol 2013;30:655. 